\title{
Tracking: emergency method or health vigilance in the retention of patients living with HIV/AIDS?
}

\author{
Hermann-Désiré Lallié ${ }^{1}$, Nicole Dakoury ${ }^{2}$, Nesma Nekkal $^{3}$, Faiçal El Hattimy ${ }^{4}$, Eric Komena ${ }^{2}$, Eugène \\ Messou ${ }^{5}$, Siaka Touré ${ }^{2}$
}

\begin{abstract}
${ }^{I}$ Péléforo GON COULIBALY University, Training and Research Unit of Biological Sciences, Department of Biochemistry and Genetics, BP 1328 Korhogo, Côte d'Ivoire.

${ }^{2}$ Non Governmental Organization ACONDA VS, Abidjan, Côte d'Ivoire

${ }^{3}$ Mohammed VI Polytechnic University, Institute of Medical, Biological and Health Professions (ISMB-MS), Lot 660 Hay Moulay Rachid 43150 Benguerir, Morocco.

${ }^{4}$ Ibn Tofail University, Faculty of Science, Laboratory of Biology and Health, BP 242 Kenitra, Morocco.

${ }^{5}$ Research and Training Support Center (CEPREF), Yopougon, Côte d'Ivoire
\end{abstract}

\begin{abstract}
There were 1.7 million HIVIAIDS-related deaths worldwide. The low retention of patients in care was a hindrance to their treatment. The objective of this study was to establish the epidemiological profile of patients, to implement "tracking" and to evaluate its effectiveness. This is a descriptive and analytical retrospective study of all patients living with HIVIAIDS enrolled from 2004 to 2012 by the non-governmental organization ACONDA-VSCI. It consisted of a series of phone calls and home visits. Results showed that $71 \%$ of the 51.703 patients enrolled were female with a sex-ratio (F/M) of 2.5. The average age of patients was $33 \pm 13$ years. $47 \%$ of the patients enrolled had an unknown vital status in 2011 and only $42 \%$ of them had a telephone number. In addition, $11 \%$ of patients with unknown vital status were contacted and reintegrated into the care system. Multivariate regression analysis showed that the lack of awareness of status in patients was related to elevated CD4s, and having spent more than three years in a health center. On the other hand, being in a relationship and living in a rural area was a protective factor against the lack of knowledge of status. At the end of this study, it appears that the tracking method is an excellent method of combating the loss of sight of patients. However, it must be carried out routinely as a method of health vigilance and not a health emergency. Keywords: HIVIAIDS; Tracking; Epidemiological profile; 90-90-90; Ivory Coast.
\end{abstract}

\section{INTRODUCTION}

At the end of 2011, the Joint United Nations Programme on HIV/AIDS (UNAIDS) counted nearly 34 million people infected with HIV/AIDS worldwide, accounting for nearly 1.7 million deaths [1].

Sub-Saharan Africa, was still the region most affected by this pandemic. It recorded more than $70 \%$ of the world's people living with HIV/AIDS (PLHIV), with about 24 million people per 1.2 million deaths that year [1].

Côte d'Ivoire, a West African country, had nearly 450.000 people infected with an estimated 36.000 deaths in 2009 [2].
In 2001, Msellati and her collaborators saw the challenge of access to treatment as a major one, as a cornerstone of the fight against HIV/AIDS [3].

For example, UNAIDS, in collaboration with these partners, has implemented a policy of facilitating access to treatment for PLHIV around the world, particularly in Africa. Côte d'Ivoire was thus one of the first countries selected in 1997 for the implementation of the initiative for access to antiretroviral treatment [3].

However, in several countries, such as Côte d'Ivoire, many PLHIV are lost to follow-up to care for several reasons, including psycho-social, sociodemographic reasons, perception of the disease, stigma, heavy treatment or dissatisfaction with care, permanent or temporary travel, etc. [4-6]. 
This challenge of bringing them back into care is essential in implementation strategies, as it contributes strongly to the retention of patients in care, to their treatment and thus promotes the achievement of the 90-90-90 UNAIDS initiative [7].

To the extent of this, the Non-Governmental Organization ACONDA-VS Côte d'Ivoire, established in 2002, and beneficiary of funds allocated by the President's Emergency Plan for AIDS Relief (PEPFAR), has decided to screen all patients enrolled in their care centers to know their vital status and to bring back, if necessary, all patients lost to follow-up (LTFU).

To reach this goal, this NGO has implemented a strategy called "tracking" which is an active method of finding patients registered in care and lost to follow-up. It is mainly based on phone calls and home visits.

The main objective of this work was first to establish the vital status of patients by describing their socio-demographic and clinical profile and secondly to implement tracking and evaluate its effectiveness as an emergency or health alertness strategy.

\section{PATIENTS ET METHODS}

\subsection{Structure}

A non-governmental organization in Côte d'Ivoire, formed since 2002, "ACONDA-VS-Côte d'Ivoire", brings together local health professionals. It is one of the main NGOs benefiting from the funds allocated by the US government in the fight against HIV/AIDS in Côte d'Ivoire, under the CDC/PEPFAR programme. She works in the specialized, psychosocial and community medical care of people living with HIV/AIDS. It relies, for this reason, on relay NGOs that implement a part of its work on the ground. Under the CDC/PEPFAR programme, the NGO managed 138 public health centers in four regions: Abidjan-1-Grands Ponts, Cavally-Guémon, Tonpki, and KabadougouBafing-Folon.

\subsection{Patients}

All patients enrolled in care in this structure from 2004 to 2012.

\subsection{Methods}

This study is a descriptive and analytical retrospective analysis of all patients enrolled in care in the health centers of the NGO ACONDA-VS from 2004 to 2012.

It took place from 31 January to 30 June 2012 and consisted of the establishment of a centralized database of individual data collected from 138 health centers.

According to the tracking strategy procedure, the first step was to highlight the listing of patients with known and unknown vital status, including those with a registered telephone number and those without an existing telephone number.

Second, a call center was set up with ten counsellors depending on the size of the health center concerned to call each of its patients with telephone number, document their vital status and the reasons for their absence from care.

Finally, patients who were not contacted by telephone and those without a telephone number were visited at home by community counsellors.

\section{RESULTS}

Since 2004, 51.703 PLHIV have been enrolled in the health centers covered by the programme in this non-governmental organization. Table 1 follows provides us with an epidemiological profile of all these patients.

Table 1: Epidemiological profile of enrolled PLHIV

\begin{tabular}{|c|c|c|}
\hline Sex & & \\
\hline Male, n (\%) & 14,668 & $(28.53 \%)$ \\
\hline Feminine, $\mathrm{n}(\%)$ & 36,750 & $(71.47 \%)$ \\
\hline \multicolumn{3}{|l|}{ Age } \\
\hline Average (Ecart-type) & 33.45 & (13.39) \\
\hline Median (IIQ) & 34 & $(27-41)$ \\
\hline \multicolumn{3}{|l|}{$\mathrm{CD} 4$, in cells/mm3 } \\
\hline Average (Ecart-type) & 444.58 & $(4,560.9)$ \\
\hline Median (IIQ) & 346 & $(181-553)$ \\
\hline \multicolumn{3}{|l|}{ In class, $n(\%)$} \\
\hline$<200$ & 10.65 & $(27.57 \%)$ \\
\hline Between 200 and 350 & 8,844 & $(22.91 \%)$ \\
\hline Between 350 and 500 & 7,358 & $(19.06 \%)$ \\
\hline$>500$ & 11,760 & $(30.46 \%)$ \\
\hline \multicolumn{3}{|l|}{ Center } \\
\hline Abidjan & 37,987 & $(73.47 \%)$ \\
\hline Outside Abidjan & 13,716 & $(26.53 \%)$ \\
\hline \multicolumn{3}{|l|}{ Centre time, year-round } \\
\hline Average (Ecart-type) & 5.77 & $(1.31)$ \\
\hline Median (IIQ) & 6 & $(4-7)$ \\
\hline \multicolumn{3}{|l|}{ In class, $n(\%)$} \\
\hline Less than 3 years & 3,087 & $(5.97 \%)$ \\
\hline Between 4 and 6 years old & 29,118 & $(56.32 \%)$ \\
\hline 7 years and older & 19,498 & $(37.71 \%)$ \\
\hline Lives in a couple & & \\
\hline
\end{tabular}




\begin{tabular}{ccc} 
Yes & 21,527 & $(56.71 \%)$ \\
No & 16,432 & $(43.29 \%)$ \\
Educational level & & \\
Out of school & 15,174 & $(38.12 \%)$ \\
primary & 11,706 & $(29.41 \%)$ \\
secondary & 10,466 & $(26.29 \%)$ \\
upper & 2,462 & $(6.18 \%)$ \\
\hline
\end{tabular}

The majority of the patients enrolled were women (71\%), the average age of these patients was $33 \pm 13$ years. They live mostly in pairs $(57 \%)$, and nearly $70 \%$ of them had CD4s below 500 cells $/ \mathrm{mm}^{3}$.

The city of Abidjan accounted for nearly threequarters of the patients monitored. Regarding the level of education, almost all (94\%) of these patients had a level below or equal to secondary school and 68\% strictly lower than high school.

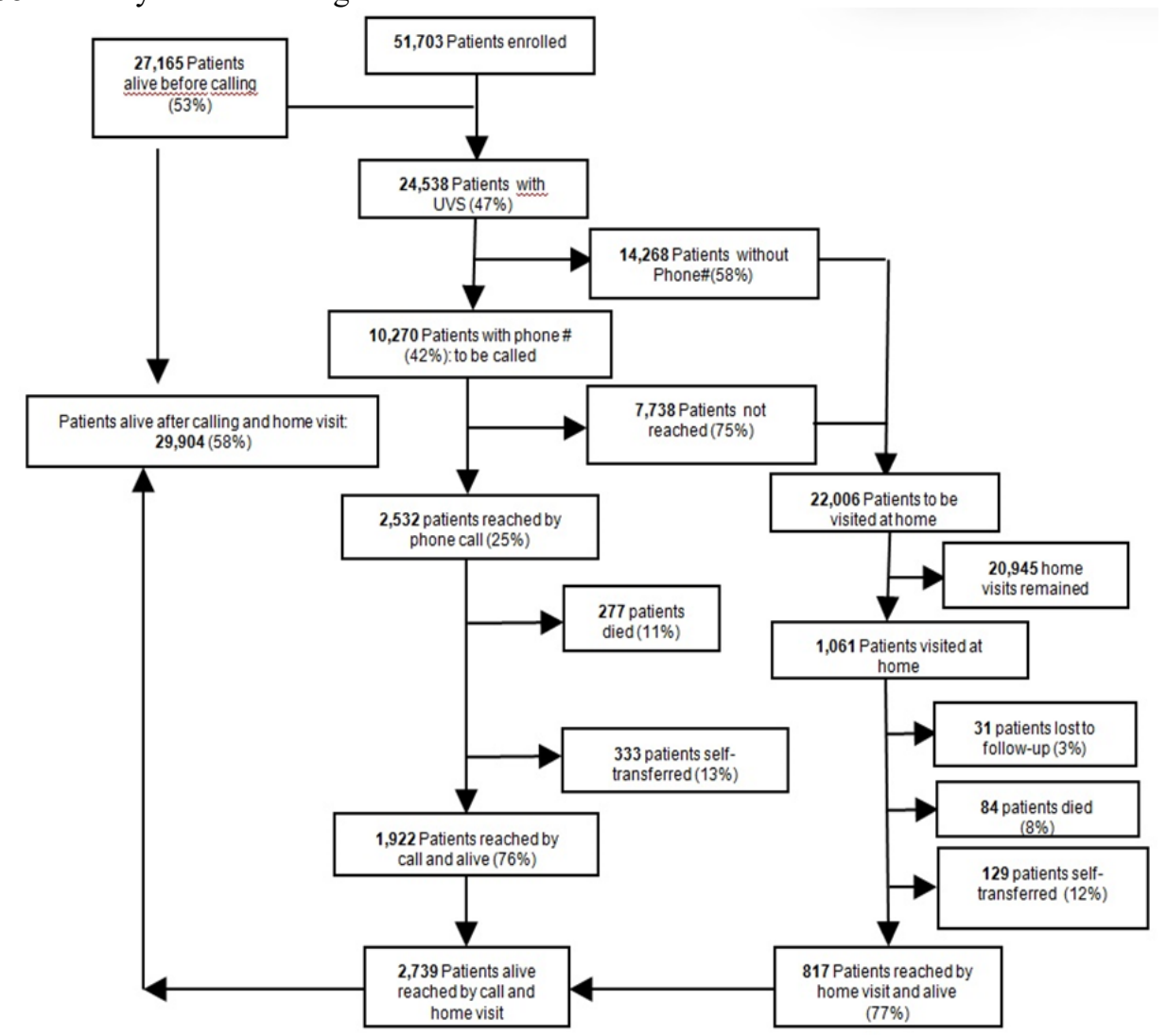

Fig.1. Patients tracking

The results on the vital status of patients, from home visits and phone calls, are presented in the following figure 2 .
The results obtained after the implementation of the tracking are presented in the following figure 1 . This figure shows that patients with unknown vital status (UVS) accounted for $47 \%$ of all patients enrolled in this structure. Of these, only $42 \%$ had a telephone number. At the end of the Call Center that followed, $75 \%$ of these patients could not be reached, certainly for reasons of false contacts, lines unreachable or interrupted or even patients without recent news (Fig.1). All patients who could not be reached and those without telephone contacts (22.006 patients) were visited at home by community counsellors. However, only 1,061 home visits $(5 \%)$ were carried out over the duration of this study. After the tracking method, 29.904 (58\%) PLHIV had their vital status documented. 
Fig.2. Vital Status of patients called and visited at home

The majority of patients called and visited at home were alive $(76 \%)$, but with a high death rate $(10 \%)$ and a self-transfer ratio nearly to $13 \%$. PLHIV who were reachable over the phone had a low selftransfer percentage of $1 \%$.

Table 2 presents the results of a multivariate regression analysis that shows the factors associated with a lack of awareness of vital status in patients.

It shows that patients with CD4s greater than 200 cells $/ \mathrm{mm}^{3}$ and those who have more than 3 years of follow-up at a center, including between 4 and 6 years, are those whose status has remained unknown.

On the other hand, living as a couple to a lesser extent and, above all, living outside Abidjan, were protective factors associated with a lack of knowledge of vital status.

Table 2: Factors Associated with Lack of Knowledge of Vital Status of PLHIV

\begin{tabular}{lccc} 
& $\begin{array}{c}\text { Odd- } \\
\text { Ratio }\end{array}$ & $\mathbf{9 5 \%} \boldsymbol{C I}$ & $\boldsymbol{P}$ \\
\hline Sex & & & $\underline{\mathbf{0 , 0 0 0}}$ \\
Male & 1 & - & \\
Female & 1,11 & $(1,05-1,18)$ & \\
CD4, in cells/mm3 & & & $\underline{\mathbf{0 , 0 0 0}}$ \\
$<200$ & 1 & - & \\
$>200$ and $<350$ & 1,24 & $(1,16-1,33)$ & \\
$>=350$ and $<500$ & 1,41 & $(1,31-1,51)$ & \\
$>=500$ & 1,34 & $(1,25-1,43)$ & \\
Center & & & $\underline{\mathbf{0 , 0 0 0}}$ \\
Abidjan & 1 & - & \\
Outside Abidjan & 0,3 & $(0,28-0,32)$ & \\
Duration on center & & & $\underline{\mathbf{0 , 0 0 0}}$ \\
$<3$ years & 1 & - & \\
$>3$ and $<6$ years & 2,33 & $(2,04-2,66)$ & \\
$>=6$ years & 1,33 & $(1,16-1,53)$ & \\
Lives in a couple & & & $\underline{\mathbf{0 , 0 0 1}}$ \\
No & 1 & & \\
Yes & 0,92 & $(0,87-0,96)$ & \\
\hline
\end{tabular}

\section{DISCUSSION}

The non-governmental organization ACONDA-VS $\mathrm{CI}$ registered in this period more than 51.000 patients or more than $11 \%$ of the national population of PLHIV in Côte d'Ivoire. The vast majority of these patients were women $(71 \%)$ with a sex ratio $(F / M)$ of 2.5 . These observations are at odds with those obtained by Soro and his team on
HIV seroprevalence in Côte d'Ivoire in 1990 where the proportion of women with HIV was $37 \%$ or a sex ratio $(\mathrm{F} / \mathrm{M})$ of 0.6 [8]. However, in line with the results of this study, two more recent surveys conducted by the Ivorian Ministry of Health and AIDS Control in 2005 and 2012 respectively established the sex ratio $(\mathrm{F} / \mathrm{M})$ at 2.2 and 1.6; almost 69 and $62 \%$ [9-10]. These proportions are well close to those observed from 2001 to 2005 in 18 sub-Saharan African countries by Garcia-Calleja and his collaborators [11]; but also observed from 2008 to 2014 in 17 sub-Saharan countries by Hanne $\mathrm{K}$. and his collaborators [12]. The difference in sex ratio in these two periods; 90 s and 2000s; could be explained by this assertion of Carpenter and his collaborators that the maturity of the epidemic is the main determinant of the sexual distribution of HIV infections [13]. They argue that in the early years of an epidemic caused by heterosexual transmission, as in the sub-Saharan context, HIV cases tend to be concentrated among sex workers and their clients, so that male prevalence exceeds female prevalence. Over time, the prevalence of women increases as the wives and non-marital partners of these male clients become infected, eventually shifting the gender balance in HIV prevalence to women [13]. It would also be wise to note that in this programme, and as has been documented many times in Sub-Saharan Africa, sentinel surveillance of pregnant women attending antenatal consultations remains the main source of information on HIV prevalence [14; 15], which would tend to increase sex ratio even further in favor of women.

The majority of patients resided in Abidjan (73\%), urban and peri-urban areas. A 2012 Demographic and Health and Multiple Indicator Survey (EDSMICS) conducted by the Ministry of Health and AIDS Control estimated that prevalence in urban areas was higher than that in rural areas at 4.3 and $3.1 \%$, respectively. It also estimated the prevalence rate of the city of Abidjan (5.1\%), as the highest of all the cities in the country [10]. This reinforces the urban status of this disease as already described in numerous publications throughout the African continent [11, 16-18].

PLHIV had a relatively low level of education, with $67 \%$ of them grading below high school. This score is quite close to that observed by EDS-MICS 2005, with $70.3 \%$ and EDS-MICS in 2012 with a rate of $79 \%$ of PLHIV with a lower level than the secondary level [9-10]. The relationship between educational attainment and HIV/AIDS prevalence is not clear. It can be linked to the country's level of development. For example, in a study described by Glynn and colleagues in 2004 in four sub-Saharan countries, HIV prevalence among educated people was low (19). In contrast, HIV/AIDS prevalence was highest among the most educated, as described 
in many studies, including Hargreaves and Glynn in a 2002 meta-analysis of the level of education and HIV-1 infection in developing countries [17-21].

After the implementation of tracking, the main reasons for loss of follow-up mentioned by living patients were forgetfulness or neglect, feeling good, being up to date in its follow-up and changing of home. These reasons are consistent with those already documented by Evangeli, Ware and Earnshaw in their different studies [4-6]. Thus, the impression of the well-being of lost patients resulting from the multivariate analysis would explain the fact that the CD4 level above 200 cells $/ \mathrm{mm}^{3}$ is a factor associated with the loss of follow-up of these patients. This finding is consistent with that obtained by Kiwanuka Julius and colleagues in their retrospective cohort study on the determinants of follow-up loss in HIVpositive patients receiving antiretroviral therapy in the context of "test and treat all" in Masaka, Uganda [22].

On the other hand, living outside Abidjan, and to a lesser extent living as a couple, would be protective factors associated with a lack of knowledge of vital status, in fact this observation was made in many capitals where people in common-law and urban areas were much more prone to volatility, loss of sight and non-compliance with care [4-5].

\section{CONCLUSION}

This study brought many patients back into care, however $42 \%$ of the 51.703 patients enrolled in this structure (21.799) could not be contacted or visited in 2011 and thus escaped the care circuits. It is therefore clear that the tracking method implemented by the NGO ACONDA VS-CI is an excellent method of retaining patients in care, but provided that it is carried out in a routine and closeup manner. Thus, it would allow patients to be brought back to the care system, to document the reasons for loss of follow-up and thus to reduce the mortality rate associated with this disease in this organism and much more generally in Côte d'Ivoire in order to achieve the 90-90-90 goals of UNAIDS.

\section{REFERENCES}

[1] Programme commun des Nations Unies sur le VIH/SIDA. Rapport ONUSIDA sur l'Epidémie Mondiale de SIDA, 2012.

[2] Rapport National GARP Côte d'Ivoire 2012, Suivi de la déclaration de politique sur le SIDA de Juin 2011.

[3] P. Msellati, L. Vidal et J.P. Moatti, "L'accès aux traitements du VIH/sida en Côte d'Ivoire. Évaluation de l'Initiative ONUSIDA/Ministère de la Santé publique" Agence Nationale de
Recherches sur le Sida, Paris : 327 pages. (2001).

[4] M. Evangeli, M.L. Newell, L. Richter, N. McGrath, The association between SelfReported Sigma and Loss-to-Follow Up in treatment eligible HIV positive adults in rural Kwazulu-Natal, South Africa, Plos One, 9(2): e88235. (2014).

[5] N.C. Ware, M.A. Wyatt, E.H. Geng, S.F. Kaaya, O.O. Agbaji, et al., Toward an Understanding of Disengagement from HIV Treatment and Care in Sub-Saharan Africa: A Qualitative Study. Plos Med, 10 (1): e1001369. (2013).

[6] V.A. Earnshaw, S.R. Chaudoir, From conceptualizing to measuring HIV stigma : a review of HIV stigma mechanism measures. AIDS Behav 13 : 1160-1177. (2009).

[7] Programme commun des Nations Unies sur le VIH/SIDA (ONUSIDA). 90-90-90 : Une cible ambitieuse de traitement pour aider à mettre fin à l'épidémie du Sida, (2014).

[8] B.N. Soro, G.M. Gershy-Damet, A. Coulibaly, K. Koffi, V.S. Sangare, D. Koffi, R. Houdier, R. Josseran, J. Guelain, E. Aoussi, et al. Seroprevalence of HIV infection in the general population of the Cote d'Ivoire, West Africa. $J$ Acquir Immune Defic Syndr, 3(12) : 1193-6. (1990).

[9] Ministère de la Santé et de la Lutte contre le SIDA. Enquête sur les Indicateurs du SIDA, Côte d'Ivoire, 2005.

[10] Ministère de la Santé et de la Lutte contre le SIDA. Enquête Démographique et de Santé et à Indicateurs Multiples, Côte d'Ivoire, 20112012.

[11] J.M. Garcia-Calleja, E. Gouws, and P.D. Ghys, National population based HIV prevalence surveys in sub-Saharan Africa: results and implications for HIV and AIDS estimates. Sex Transm Infect, 82 (Suppl III): iii64-iii70. (2006).

[12]H.K. Hegdahl, K.M Fylkesnes., I.F. Sandøy, Sex Differences in HIV Prevalence Persist over Time : Evidence from 18 Countries in SubSaharan Africa. PLoS ONE, 11(2) : e0148502. (2016).

[13] L.M. Carpenter, A. Kamali, A. Ruberantwari, S.S. Malamba, J.A.G. Whitworth. Rates of HIV-1 transmission within marriage in rural Uganda in relation to the HIV sero-status of the partners. AIDS, 13 :1083-1089. (1999).

[14]J. Chin, J. Mann. Global surveillance and forecasting of AIDS. Bull World Health Organ ;67 :1-7. (1989).

[15]P.D. Ghys, E. Kufa, and M.V. George for the UNAIDS Reference Group on Estimates Modelling and Projections' ad hoc Working Group on interpreting trends in prevalence and incidence of HIV infection in countries with 
generalised epidemics. Measuring trends in prevalence and incidence of HIV infection in countries with generalised epidemics. Sex Transm Infect, 82, Suppl 1: i52-i56. (2006).

[16]L.S. Montana, V. Mishra, R. Hong, Comparison of HIV prevalence estimates from antenatal care surveillance and populationbased surveys in sub-Saharan Africa. Sex Transm Infect; 84 Suppl 1:i78-i84. (2008).

[17] N. Kayeyi, K. Fylkesnes, C. Michelo, M. Makasa, I. Sandøy, Decline in HIV Prevalence among Young Women in Zambia: NationalLevel Estimates of Trends Mask Geographical and Socio-Demographic Differences. PloS one, 7(4):e33652. (2012).

[18] M. Hajizadeh, D. Sia, S. Heymann, A. Nandi, Socioeconomic inequalities in HIV/AIDS prevalence in sub-Saharan African countries : evidence from the Demographic Health ,Surveys. International Journal for Equity in Health; 13(1):18. (2014).
[19] J.R. Glynn, M. Caraël, A. Buvé, S. Anagonou, L. Zekeng, M. Kahindo, R. Musonda, Does increased general schooling protect against HIV infection? A study in four African cities. Trop Med Int Heal, 9 :4-14. (2004)

[20] J.G. Fortson, The gradient in sub-Saharan Africa: Socioeconomic status and HIV/AIDS. Demography; 45(2):303-22. PMID : 18613483. (2008).

[21] J.R. Hargreaves, J.R. Glynn, Educational attainment and HIV-1 infection in developing countries : a systematic review. Trop Med Int Heal,7 :489-498. (2002).

[22] J. Kiwanuka, J.M. Waila, M.M. Kahungu, J. Kitonsa, N. Kiwanuka, Determinants of loss to follow-up among HIV positive patients receiving antiretroviral therapy in a test and treat setting : A retrospective cohort study in Masaka, Uganda, PLoS One ; 15(4) : e0217606. (2020). 